\title{
Myoepithelioma of the tongue-clinicopathological and immunohistochemical features
}

\author{
Estefanía Alvarez B,' Cristobal Sepulveda, ${ }^{2}$ Liberto Figueroa $C^{1,2,3}$ \\ 'Facultad de salud y odontología, Universidad Diego Portales, Chile \\ ${ }^{2}$ Facultad de salud y odontología UDP, Universidad Diego Portales, Chile \\ ${ }^{3}$ Servicio de Cirugía Maxilofacial Clínica Alemana Santiago, Chile
}

Correspondence: Estefania Alvarez, Facultad de salud y odontología, Universidad Diego Portales, Vital Apoquindo I380, casa 26. Las Condes, Santiago de Chile, Tel +56 02 22II4452/+56966495448,Email eealvarezb@gmail.com/ealvarezb@udd.cl

Received: June 08, 2018 | Published: June 14, 2018

Copyright@ 2018 Alvarez et al. This is an open access article distributed under the terms of the Creative Commons Attribution License, which permits unrestricted use, distribution, and reproduction in any medium, provided the original author and source are credited.

\begin{abstract}
Myoepithelioma is a rare neoplasm in the salivary glands, and was recognised as a histologically distinct entity by the WHO in 1991 . These tumours stem from myoepithelial cells, found in secretory organs such as salivary, lacrimal sweat and mammary glands. The purpose of this article is to review the recently published scientific literature regarding this disease and to present a related clinical case study.

To find relevant literature for this study, a search was conducted in the PubMEd database for articles published between 1990-2014 containing the terms "myoepithelioma AND tongue." The clinical case study concerns a 15-year-old female patient who was referred to the maxillofacial surgery unit of the Clinica Alemana clinic in Santiago with a lingual nodule that had been under observation, and that had grown slowly and asymptomatically for a year.

The patient was given an excisional biopsy on the affected area, revealing a tumour composed of fusiform epithelioid cells with round nuclei. The immunohistochemical profile shows positive staining for vimentin and p63, drawing the definitive diagnosis of myoepithelioma of the tongue. Our work led us to the conclusion that myoepithelioma is a very rare disease and that its definitive diagnosis can only be arrived at after histopathological and immunohistochemical testing.
\end{abstract}

\section{Introduction}

Myoepithelioma is a rare neoplasm in the salivary glands, and was recognised as a histologically distinct entity by the WHO in $1991 .^{1-3}$ These tumours stem from myoepithelial cells, found in secretory organs such as salivary, lacrimal sweat and mammary glands. ${ }^{4,5}$ In the salivary glands, they are found in the ducts and acini. ${ }^{5}$ This disease represents $1.5 \%$ of all major and minor salivary gland tumours. ${ }^{1,3}$ This is a very low percentage when we take into account that salivary gland tumours are of low incidence in the first place. Ávila and Salgado ${ }^{3,6}$ determined that parotid tumours are uncommon and account for only $3 \%$ of all tumours found in the head and neck, and only $0.6 \%$ of tumours found throughout the body. Meanwhile other authors assert that they account for less than $1 \%$ of salivary gland tumours. ${ }^{2,4,6-8}$ In 2003 , Suba indicated the presence of 40 cases found in the literature. ${ }^{7}$

The most frequent location for these tumours is the parotid gland, in over $40 \%$ of cases, followed by the palate. ${ }^{1,8}$ Other authors indicate only the parotid gland as the most common location, ${ }^{5,7}$ although in extreme cases the tumours can appear in other areas, as indicated by Agarwal, ${ }^{5}$ such as the respiratory tract glands, where they may grow in the nasal cavity, nasopharynx, larynx or lungs. The tumours appear when patients are in their $40 \mathrm{~s}$ or $50 \mathrm{~s}$ and do not show a preference for gender. ${ }^{1,4,5,9}$ Other authors including Hwan and Agarwal indicate that there is a higher frequency of occurrence with patients in their $30 \mathrm{~s}^{2,5}$

Tumours of this kind are slow growing and can be asymptomatic for years, although they may become locally aggressive., ${ }^{2,469}$ They are believed to arise as a result of pleomorphic adenoma, and over time may become malignant, although when they are locally aggressive, they are believed to be de novo tumours. ${ }^{7}$ Until recently, these tumours were considered to be a variation of pleomorphic adenoma and not a distinct entity due to both these tumours being composed of epithelial cells. Distinguishing between the two is essential as today we know that myoepithelioma is a mixed tumour and despite behaving in a similar way to pleomorphic adenoma, it can become malignant.

\section{Material and method}

The purpose of this article is to review recently published scientific literature regarding this disease and to present a related clinical case study. The documents used were obtained via a bibliographical search of the PubMed database. To this end, only articles published between 1990 and October 2014 were considered. The terms used as criteria on PubMed were ' myoepithelioma AND tongue'. For the development of this article, we protected the identity and privacy of the patient and have in our possession an informed consent, consideration the ethical standards required.

\section{Clinical case report}

A 15-year-old female patient was referred by her paediatrician for the evaluation of a lingual nodule on the left-hand side of her tongue. Upon arrival at the maxillofacial surgery unit of the Clinica Alemana clinic in Santiago, the patient reported that her lingual nodule had been growing slowly and asymptomatically for a year. In terms of 
her medical history, the patient has no underlying or pre-existing conditions, and thus is classified as ASA1. A physical examination identified a renitent nodule of approximately $6 \mathrm{~mm}$ in diameter on the left anterolateral. The nodule was asymptomatic and there were no alterations in the lingual epithelium (Figure 1).

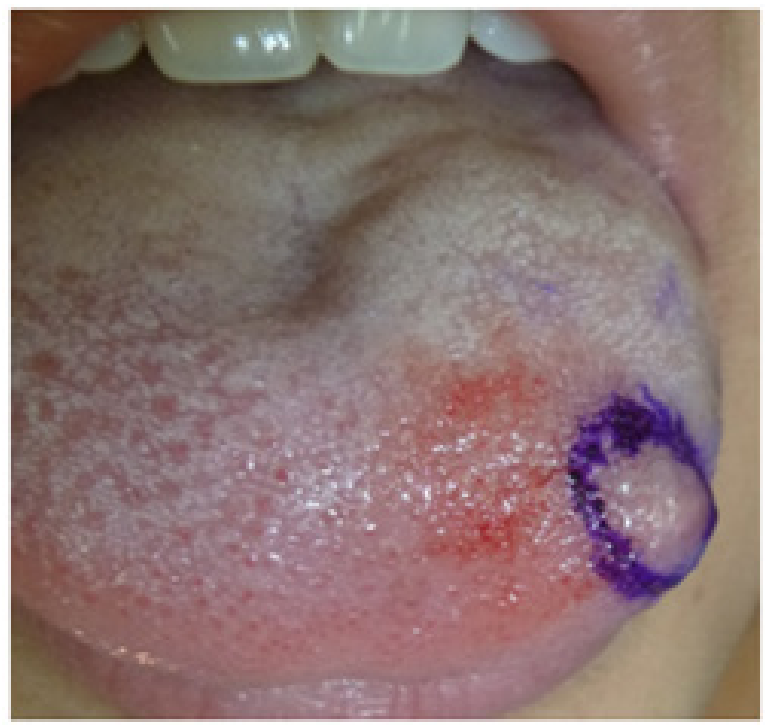

Figure I Preview

An Echo-Doppler scan was taken on the soft tissue, which indicated the formation of a submucosal nodule in contact with the muscular plane. The nodule was round, well defined, homogenous, hypoechoic and of $6 \mathrm{~mm}$ in diameter. The Doppler colour (Figure 2) showed only a small vascular arterial structure on its interior, with low-resistance flow, and determined this to be a hypovascular lesion. Afterwards an excisional biopsy was conducted under general anaesthetic, of which samples were sent for histopathological evaluation. The tumour was yellow-brown in colour, and firm. There has been no report of recurrence after 12 months (Figure $3 \&$ Figure 4).

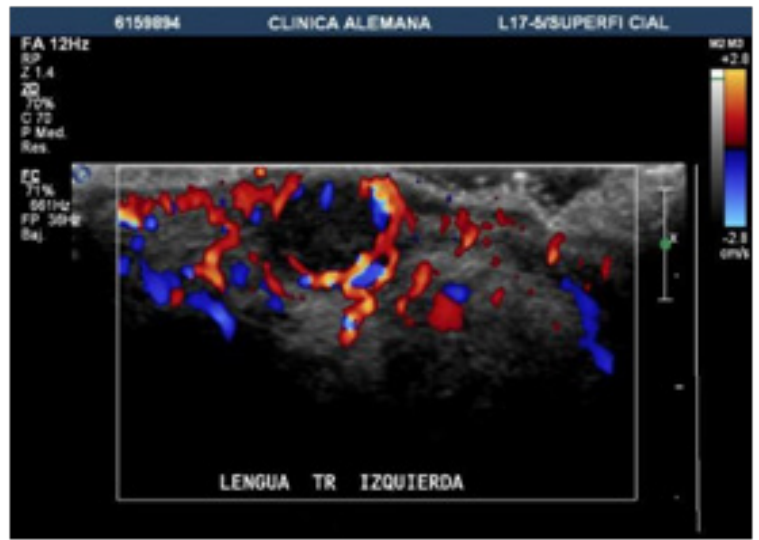

Figure 2 Echo-doppler colour

A microscopic evaluation of the simple revealed a tumoral lesion composed of fusiform epithelioid cells with round or slightly ovoid nuclei and eosinophilic cytoplasm with poorly defined contours. Along with scarce fibrocollagenous stroma with myxoid zones. The immunohistochemical profile was carried out using antibodies against S-100 protein, cytokeratins (AE1/3), vimentin, p 63, GFAP, Actin 1A4 and CD57 (Leu-7). The tumour cells only showed positive staining with vimentin and p63 (Figure 5 \& Figure 6).

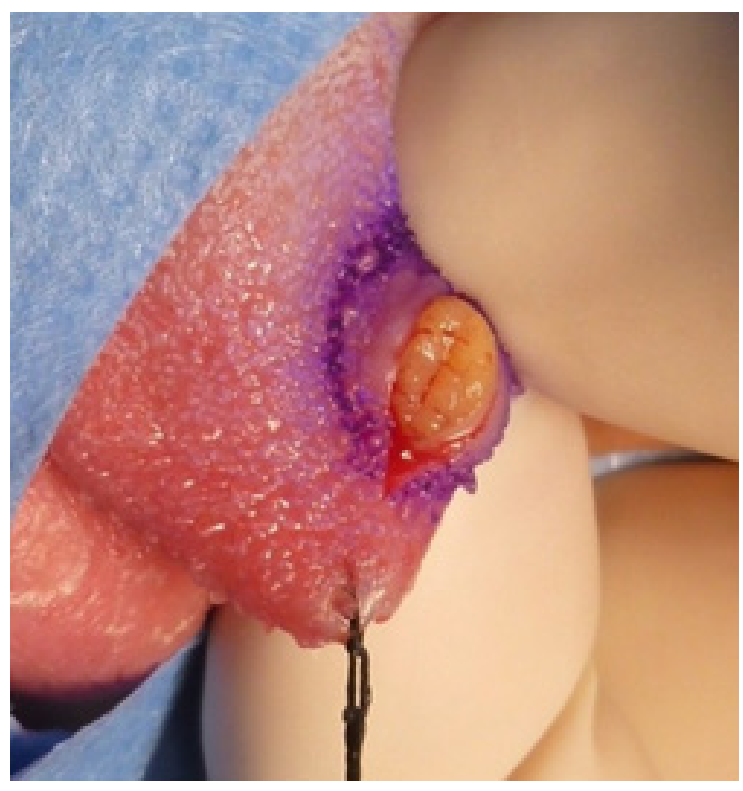

Figure 3 Excisional biopsy

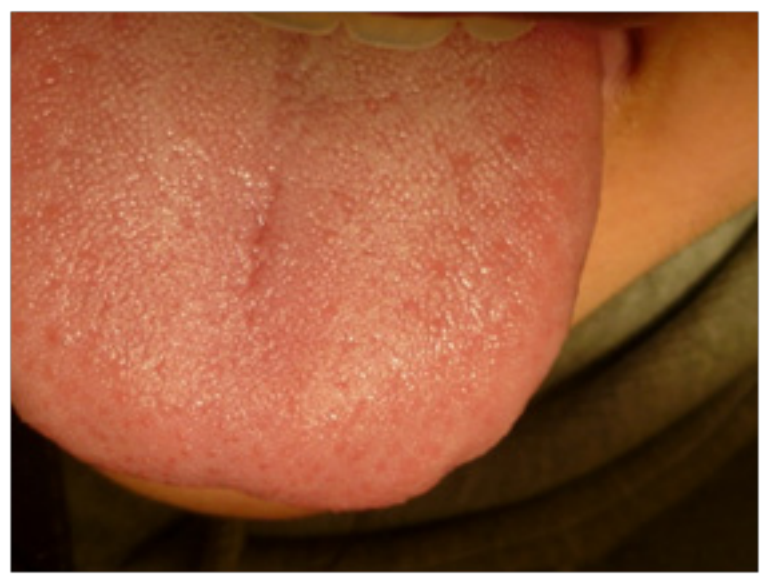

Figure 46 month control

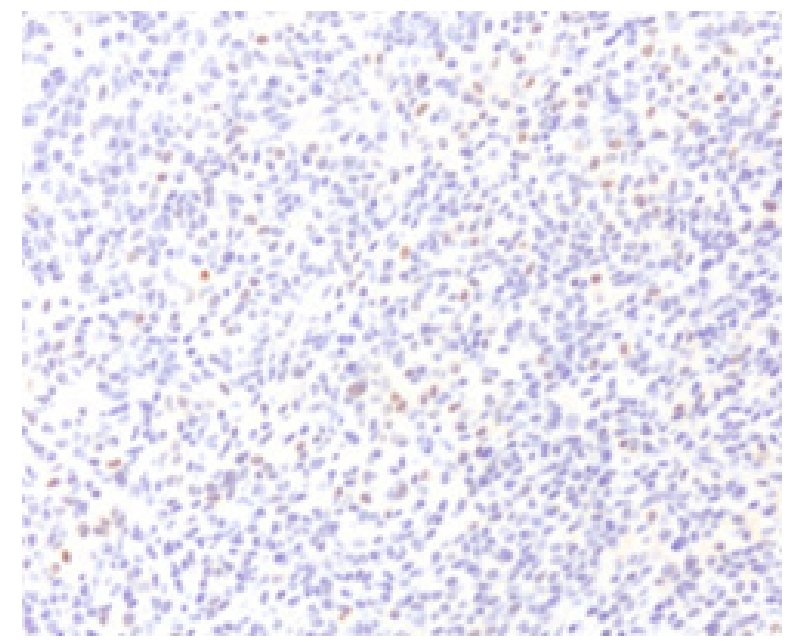

Figure 5 P63
Citation: Alvarez BE, Sepulveda C, Figueroa CL, et al. Myoepithelioma of the tongue-clinicopathological and immunohistochemical features.J Dent Maxillofacial Res. (2018);I(I):26-29. DOI: I0.3088I/jdsomr.00007 


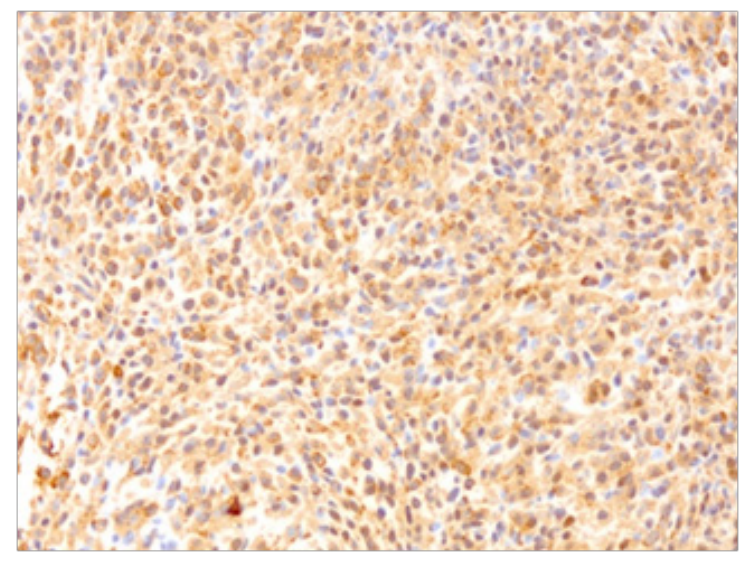

Figure 6 Vimentina.

Mitotic index: 2 mitoses/10 high-power fields.

Proliferation factor Ki67: positive in approximately 2-3\% of the tumour cells. Based on the histological findings and the positive expressions of p63 and vimentin, a definitive diagnosis of myoepithelioma of the tongue was made.

\section{Discussion}

Myoepithelioma of soft tissue is a benign neoplasm that is generally found in the subcutaneous or subfascial tissue of the extremities. ${ }^{9}$ This case shows one of the few myoepitheliomas of the tongue to have recorded in scientific literature. Histologically, myoepithelioma of soft tissue shows variety in terms of its structural pattern with a tendency towards nests, cords and sheets of neoplastic cells. The cells take on polygonal, ovoid, round, spindle and/or plasmocyte shape with central nuclei eosinophilic cytoplasm. The stroma is myxoid or chondromyxoid with areas showing hyalinization. Occasionally, squamous metaplasia and calcification may be observed. ${ }^{9}$

The immunohistochemical markers showed heavy staining from vimentin, cytokeratins (CK's), specific muscular actin (HHF-35) and protein S-100. ${ }^{7,9-11}$ Staining was variable for glial fibrally acidic protein (GFAP), epithelial membrane antigen (EMA), smooth muscle actin (SMA), CD57 (Leu-7) and p63. ${ }^{9}$ Woo,,${ }^{10}$ indicates variable staining for SMA, cytokeratin, S-100, vimentin and GFAP. Ávila indicates protein S-100 with moderate staining tumour cell cytoplasm and very heavy staining in the nuclei. ${ }^{3}$

The previous medical imaging tests that must be carried out include ultrasound, computerised tomography (CT) and resonance to determine the location and size of the growth. ${ }^{4}$ We asked for an ultrasound and that allowed us to ascertain this data: the lesion was located in the submucosal layer, in contact with the muscular plane. The scan also showed the lesion's diameter to be $6 \mathrm{~mm}$ and that it was homogenously round.

In cases of myoepithelioma, the indicated treatment is excision with a safety margin, although in our case, after the excisional biopsy was carried out the patient made good post-surgical progress without relapse, the decision was taken to not intervene further. In an ideal treatment scenario, it may be possible to dissect the local ganglion chain and then begin radiotherapy., ${ }^{2,47}$ Once the treatment is finished, long-term monitoring must be carried out to evaluate possible relapse. ${ }^{2,4}$ Radiotherapy should only be used when surgery is not a viable option. ${ }^{5}$

The majority of these tumours are benign, but the histopathological distinction must always be made. Prognoses are closely related to this kind of evaluation, as they depend on the lesion's malignancy. The available literature indicates a $90 \%$ survival rate after 5years for pleomorphic adenoma with low levels of differentiation. In contrast with other tumours that are differentiated or have invaded more than $8 \mathrm{~mm}$ into the residual capsule. However, for $\mathrm{Ca}$ in situ, the prognosis is similar to that for a mixed benign tumour. In the case of malignant myoepithelioma, the survival rate varies between $25 \%$ and $65 \%$, falling as low as $10 \%-35 \%$ after $15 y$ years. Other authors such as Agarwal ${ }^{5}$ believe that the prognosis is good, as long as there is total excision and that radiotherapy is only advisable if a mistake is made with the margins of the excision.

The histological malignancy findings indicate a high mitotic index, and infiltrating growth pattern, pleomorphism, atypical cytology and areas of necrosis. ${ }^{4,7}$ A malignant formation usually occurs in the long term with untreated tumours or recurrent benign tumours. In spite of being locally invasive, distant metastasis with this type of tumour is uncommon. ${ }^{4}$ The literature suggests that an evaluation of cell proliferation may be useful in the differential diagnosis of benign and malignant myoepithelioma, and that a Ki-67 index score of over $10 \%$ can be used to diagnose myoepithelial carcinoma. ${ }^{2,5}$

The diagnostic differentiation principally rules out pleomorphic adenoma, as although both are mixed tumours, they can be histologically differentiated thanks to the abundant channels, myoepithelial cell variability and the absence of dense areas of chondroids found in pleomorphic adenoma., ${ }^{3,4}$ Also, a differential diagnosis must be made to rule out neurofibromas, myoma, schwannoma and rhabdomyosarcoma. ${ }^{2,3}$ The diagnosis must always be based on histopathological and histochemical evaluations. Microscopically, myoepithelioma has a number of patterns; solid, myxoid (akin to pleomorphic adenoma), reticular and mixed..$^{2-5,8,9}$

Our study leads us to the conclusion that a definitive diagnosis is complex and requires histopathological and immunohistochemical evaluation. We believe that nowadays immunohistochemical markers are the only tests that allow for the differentiation of myoepithelioma from other benign and malignant tumours of the salivary glands. However it would appear that the prognosis is always positive regardless of whether the myoepithelioma is malignant, as there are no cases of relapse in the available literature after surgical intervention.

\section{Acknowledgements}

None.

\section{Conflict of interest}

The present authors have no conflict of interest with any of the issues presented or related to this clinical case.

\section{References}

1. Cuesta M, Navarro C, Duarte B, et al. Intraosseous myoepithelioma of the maxilla: clinicopathologic features and therapeutic considerations. J Oral Maxillofac Surg. 2008;66(4):800-803.
Submit your Article | www.ologypress.com/submit-article

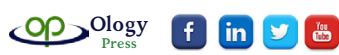

Citation: Alvarez BE, Sepulveda C, Figueroa CL, et al. Myoepithelioma of the tongue-clinicopathological and immunohistochemical features.J Dent Maxillofacial Res. (20I8); I (I):26-29. DOI: I0.3088I/jdsomr.00007 
2. Hwan T, Won S. Diagnostic challenges of myoepithelioma arising from a minor salivary gland. J Oral Maxillofac Surg. 2011;69(11):2830-2832.

3. Avila R, Samar ME, Fonseca I, et al. Mioepitelioma de parótida: estúdio histológico, histoquímico e inmunohistoquímico. Revista electrónica, Universidad del jaen. Ini Inv. 2008;3:4.

4. Yaman H, Gerek M, Tosun F, et al. Myoepithelioma of the parotid gland in a child: A case report. J Pediatr Surg. 2010;45(7): E5-E7

5. Agarwal S, Jagade M, Mishra, et al. Myoepithelioma of tongue. Int J Otolaryngology and Head \& Neck Surgery. 2013;2(1):8-10

6. Salgado N, Moncada B, Toranzo JM. Carcinoma mucoepidermoide parotideo de alto grado enmascarado por una infección cervical. Rev ADM. 2003;60(2):72-75.
7. Suba Z, Gyulai-Gaa S, Szende B. Malignant myoepithelioma. Clinicopathological and immunohistochemical characteristics. Int J Oral Maxillofac Surg. 2003;32(3):339-341

8. Liceaga R, Fuentemayor L, Mosqueda A, et al. Mioepitelioma intraóseo, presentación de un caso y revisión de la literatura. RAAO. 2012;L(1).

9. Nikitakis N, Argyris P, SklavounouA, Papadimitriou J. Oral myoepithelioma of soft tissue origin: reporto f a new case and literature review. Oral Surg Oral Med Oral Pathol Oral Radiol Endod. 2010;110(5):e48e51.

10. Woo V, Angiero F, Fantasia J. Myoepithelioma of the tongue. Oral Surg Oral Med Oral Pathol Oral Radiol Endod. 2005;99(5):581-589.

11. De Las Casas LE, Hoerl HD, Oberley TD, et al. Myoepithelioma presenting as a midline cystic toungue lesion: cytology, histology, ancillary Studies, and differential diagnosis. Diagn Cytopathol. 2001;24(6):403-407. 